\title{
MENENTUKAN AKAR PERSAMAAN NONLINIER DENGAN METODE APPROKSIMASI LINGKARAN
}

\author{
FADLI FRAYUDI, SUSILA BAHRI, NOVA NOLIZA BAKAR \\ Program Studi Matematika, \\ Fakultas Matematika dan Ilmu Pengetahuan Alam, Universitas Andalas, \\ Kampus UNAND Limau Manis Padang, Indonesia, \\ Frayudi25@gmail.com
}

\begin{abstract}
Abstrak. Penelitian ini bertujuan untuk menentukan akar dari suatu persamaaan nonlinier dengan menggunakan Metode Approksimasi Lingkaran. Dengan menggunakan metode ini, akar dari persamaan nonlinier dapat ditemukan melalui dua pendekatan, yaitu Teknik Singgung Luar Lingkaran dan Teknik Perpotongan Ortogonal Lingkaran. Misalkan $x_{0}$ adalah taksiran awal untuk akar persamaan $f(x)=0$, kemudian asumsikan $x_{1}=x_{0}+h$ dimana $h$ adalah bilangan positif atau negatif kecil. Pada kasus pertama, sebuah lingkaran $C_{1}$ dengan jari-jari $f\left(x_{0}\right)$ digambarkan dengan pusat pada sebarang titik $\left(x_{0}, f\left(x_{0}\right)\right)$ terhadap kurva fungsi $f(x)$. Lingkaran yang lainnya yaitu $C_{2}$ dengan jari-jari $f\left(x_{0}+h\right)$ dan pusat pada $\left(x_{0}+h, f\left(x_{0}+h\right)\right)$, digambarkan terhadap kurva fungsi $f(x)$ sedemikian sehingga menyinggung atau berpotongan dengan lingkaran $C_{1}$ secara eksternal atau ortogonal. Pada kasus yang kedua, sebuah lingkaran $C_{1}$ dengan jari-jari $f\left(x_{0}+h\right)$ digambarkan dengan titik pusat $\left(x_{0}+h, f\left(x_{0}+h\right)\right)$ terhadap kurva fungsi $f(x)$. Lingkaran yang lainnya yaitu $C_{2}$ dengan jari-jari $f\left(x_{0}-h\right)$ dan pusat pada $\left(x_{0}-h, f\left(x_{0}-h\right)\right)$ digambarkan terhadap kurva fungsi $f(x)$ sedemikian sehingga menyinggung atau berpotongan dengan lingkaran $C_{1}$ secara eksternal atau ortogonal. Proses iterasi pada kedua kasus tersebut bergantung pada nilai taksiran awal $\left(x_{0}\right)$ yang diambil, semakin dekat nilai taksiran awal yang diambil dengan akar sejatinya, maka akan semakin cepat proses iterasi dalam menentukan akar dari persamaan nonlinier yang diinginkan.
\end{abstract}

Kata Kunci: Persamaan Nonlinier, Teknik Singgung Luar Lingkaran, Teknik Perpotongan Ortogonal Lingkaran, Metode Approksimasi Lingkaran

\section{Pendahuluan}

Hampir semua teknik iterasi yang digunakan untuk memperoleh solusi atau akar dari sebuah persamaan nonlinier, memerlukan pengetahuan tentang taksiran awal. Salah satu cara untuk menentukan taksiran awal dapat diperoleh dengan menggunakan tabulasi nilai, yaitu dengan membuat tabel nilai dari fungsi $f(x)$ pada beberapa titik tertentu. Berberapa jenis metode yang digunakan dalam menentukan akar-akar persamaan nonlinier adalah Metode Bagi Dua, Regula-falsi, Modifikasi Regula-falsi, Secant, Newton, Muller, Laguerre, Lehmer, Graffe's root squaring dan Bairstow's. Salah satu metode baru dalam menyelesaikan persamaan nonlinier adalah Metode Approksimasi Lingkaran. Metode Approksimasi Lingkaran adalah metode yang dikembangkan oleh Vinay Kanwar, Sukhjit Singh, J.R Sharma dan Mamta dari Sant Longowal Institute of Engineering and Technology yang telah dipublikasi dalam sebuah jurnal internasional yang berjudul New Numerical Techniques for Solving Nonlinear Equations. Dalam penelitian ini akan dikaji ulang 
Metode Approksimasi Lingkaran.

\section{Persamaan Nonlinier}

Persamaaan nonlinier adalah persamaan yang grafik fungsinya tidak membentuk garis lurus. Jenis-jenis dari persamaan nonlinier diantaranya:

(1) Persamaan Aljabar.

Persamaan aljabar yang termasuk dalam persamaan nonlinier adalah persamaan dalam bentuk:

- Polinomial (Suku Banyak).

Polinomial atau suku banyak satu variabel secara umum dapat dinyatakan sebagai $f(x)=a_{0}+a_{1} x+a_{2} x^{2}+\ldots+a_{n} x^{n}$ dimana $a$ adalah konstanta.

- Persamaan Rasional.

Persamaan rasional adalah persamaan yang dapat ditulis dalam bentuk $p(x) / q(x)$, dimana $p(x)$ dan $q(x)$ adalah polinomial dan $q(x) \neq 0$.

(2) Persamaan Transenden

Fungsi transenden atau fungsi non-aljabar adalah fungsi yang tidak dapat dinyatakan dalam fungsi aljabar. Fungsi transenden terdiri dari fungsi eksponensial, fungsi logaritma, fungsi trigonometri dan fungsi hiperbolik.

\subsection{Akar}

Bilangan $r$ disebut akar dari suatu persamaan polinomial $f(x)=0$ jika dan hanya jika $f(r)=0$. Berikut ini diberikan teorema lokasi akar:

Teorema 2.1. [1] Misalkan $I=[\alpha, \beta]$ adalah suatu interval dan misalkan $f: I \rightarrow$ $R$ kontinu di I. Jika $\alpha<\beta$ adalah bilangan-bilangan pada I sedemikian sehingga $f(\alpha)<0<f(\beta)$, maka terdapat suatu bilangan $c \in[\alpha, \beta]$ sedemikian sehingga $f(c)=0$.

\subsection{Metode Pencarian Akar}

Metode numerik untuk mencari akar fungsi secara umum terbagi dua, yaitu metode pengurung dan metode terbuka. Pada metode pengurung, akar yang dicari selalu diapit atau dikurung dalam suatu interval. Proses ini selalu konvergen meskipun kekonvergenannya lebih lambat dibanding metode terbuka. Contoh metode pengurung adalah Metode Bagi Dua, Metode Regula Falsi. Sebaliknya pada metode terbuka akar tidak perlu diapit interval. Proses pada metode ini tidak selalu konvergen, tetapi bila proses tersebut konvergen, maka kekonvergenannya lebih capat dibanding metode pengurung. Contoh dari metode terbuka adalah Metode Iterasi Sederhana, Metode Newton-Raphson, Metode Secant. 
40 Fadli Frayudi, Susila Bahri, Nova Noliza Bakar

\subsection{Deret Taylor}

Deret Taylor dapat ditulis sebagai berikut:

$$
\begin{aligned}
f\left(x_{i+1}\right)= & f(x)+f^{\prime}\left(x_{i}\right)\left(x_{i+1}-x_{i}\right)+\frac{f^{\prime \prime}\left(x_{i}\right)}{2 !}\left(x_{i+1}-x_{i}\right)^{2} \\
& +\frac{f^{\prime \prime \prime}\left(x_{i}\right)}{3 !}\left(x_{i+1}-x_{i}\right)^{3}+\ldots+\left(x_{i+1}-x_{i}\right)^{n}+R_{n},
\end{aligned}
$$

dimana

$$
R_{n}=\frac{f^{n+1}(\xi)}{(n+1) !}\left(x_{i+1}-x_{i}\right)^{n+1}
$$

\subsection{Galat}

Galat adalah perbedaan nilai dari suatu besaran antara nilai eksak (nilai sebenarnya) dengan nilai hampirannya.

$$
E=x-x^{*}
$$

$x$ adalah nilai eksak dari besaran, $x^{*}$ adalah nilai hampirannya dan $E$ adalah galat mutlak dari $x$.

\subsection{Lingkaran}

Lingkaran adalah himpunan titik-titik pada jarak tetap (jari-jari) dari suatu titik (pusat). Lingkaran adalah contoh dari kurva tertutup sederhana. Suatu lingkaran memiliki persamaan:

$$
\left(x-x_{0}\right)^{2}+\left(y-y_{0}\right)^{2}=R^{2},
$$

dengan $R$ adalah jari-jari lingkaran dan $\left(x_{0}, y_{0}\right)$ adalah koordinat pusat lingkaran.

\section{Pembahasan}

Akan diuraikan Metode Approksimasi Lingkaran untuk dua jenis kasus, yaitu lingkaran dengan titik pusat $\left(x_{0}, f\left(x_{0}\right)\right)$ dan lingkaran dengan titik pusat $\left(x_{0}+\right.$ $\left.h, f\left(x_{0}+h\right)\right)$. Penentuan akar masing-masing kasus dilakukan melalui dua pendekatan yaitu Teknik Singgung Luar Lingkaran dan Teknik Perpotongan Ortogonal Lingkaran.

Misalkan persamaan

$$
f(x)=0,
$$

mempunyai satu atau lebih akar. Misalkan:

$$
y=f(x)
$$

menyatakan grafik dari fungsi $f(x)$ dan asumsikan bahwa sebuah taksiran awal $x_{0}$ untuk akar persamaan (3.1) diketahui. Kemudian misalkan:

$$
x_{1}=x_{0}+h, \quad|h|<<1
$$

adalah approksimasi pertama untuk akar yang diinginkan dari persamaan (3.1). 


\subsection{Lingkaran Dengan Titik Pusat $\left(x_{0}, f\left(x_{0}\right)\right)$}

Asumsikan taksiran awal $x_{0}$ untuk persamaan (3.1) diketahui. Sebuah lingkaran $C_{1}$ dengan jari-jari $f\left(x_{0}\right)$ digambarkan dengan pusat pada sebarang $\left(x_{0}+h, f\left(x_{0}+h\right)\right)$, dimana $h$ adalah bilangan positif atau negatif kecil, digambarkan terhadap kurva fungsi $f(x)$ sedemikian sehingga menyinggung atau berpotongan dengan lingkaran $C_{1}$ secara eksternal atau ortogonal.

(1) Teknik Singgung Luar Lingkaran.

Lingkaran $C_{2}$ akan menyinggung lingkaran $C_{1}$ secara eksternal jika:

$$
\begin{aligned}
f\left(x_{0}+h\right)+f\left(x_{0}\right) & =\sqrt{\left(x_{0}+h-x_{0}\right)^{2}+\left(f\left(x_{0}+h\right)-f\left(x_{0}\right)\right)^{2}}, \\
h^{2}-4 f\left(x_{0}\right) f\left(x_{0}+h\right) & =0, \\
h^{2}-4 f\left(x_{0}\right)\left\{f\left(x_{0}\right)+h f^{\prime}\left(x_{0}\right)+\ldots\right\} & =0, \\
h^{2}-4 f\left(x_{0}\right) f^{\prime}\left(x_{0}\right)-\left(4 f\left(x_{0}\right)^{2}\right) & =0,
\end{aligned}
$$

maka didapatkan nilai $h$, yaitu:

$$
h=\frac{-2 f\left(x_{0}\right)}{f^{\prime}\left(x_{0}\right) \pm \sqrt{1+\left(f^{\prime}\left(x_{0}\right)\right)^{2}}},
$$

dimana tanda \pm harus dipilih sehingga membuat penyebut paling besar. dengan menggunakan persamaan (3.4) kedalam (8.3) akan didapatkan approksimasi pertama dari akar, yaitu:

$$
x_{1}=x_{0}-\frac{2 f\left(x_{0}\right)}{f^{\prime}\left(x_{0}\right) \pm \sqrt{1+\left(f^{\prime}\left(x_{0}\right)\right)^{2}}}
$$

Secara umum, approksimasi dapat ditentukan dengan:

$$
x_{n+1}=x_{n}-\frac{2 f\left(x_{n}\right)}{f^{\prime}\left(x_{n}\right) \pm \sqrt{1+\left(f^{\prime}\left(x_{n}\right)\right)^{2}}},(n \geq 0)
$$

(2) Teknik Perpotongan Ortogonal Lingkaran

Lingkaran $C_{2}$ akan berpotongan dengan lingkaran $C_{1}$ secara ortogonal jika:

$$
\begin{aligned}
\left(f\left(x_{0}+h\right)\right)^{2}+\left(f\left(x_{0}\right)\right)^{2} & =\left(x_{0}+h-x_{0}\right)^{2}+\left(f\left(x_{0}+h\right)-f\left(x_{0}\right)\right)^{2}, \\
h^{2}-2 f\left(x_{0}\right) f\left(x_{0}+h\right) & =0, \\
h^{2}-2 f\left(x_{0}\right)\left\{f\left(x_{0}\right)+h f^{\prime}\left(x_{0}\right)+\ldots\right\} & =0,
\end{aligned}
$$

dimana

$$
h=f\left(x_{0}\right)\left(\left(f^{\prime}\left(x_{0}\right)\right)^{2} \pm \sqrt{2+f^{\prime}\left(x_{0}\right)}\right) .
$$

Oleh karena itu approksimasi pertama dari akar, yaitu:

$$
x_{1}=x_{0}-\frac{2 f\left(x_{0}\right)}{f^{\prime}\left(x_{0}\right) \pm \sqrt{2+\left(f^{\prime}\left(x_{0}\right)\right)^{2}}}
$$

Secara umum, approksimasi dapat ditentukan dengan:

$$
x_{n+1}=x_{n}-\frac{2 f\left(x_{n}\right)}{f^{\prime}\left(x_{n}\right) \pm \sqrt{2+\left(f^{\prime}\left(x_{n}\right)\right)^{2}}} .
$$




\subsection{Lingkaran Dengan Titik Pusat $\left(x_{0}+h, f\left(x_{0}+h\right)\right)$}

Sebuah lingkaran $C_{1}$ dengan jari-jari $f\left(x_{0}+h\right)$ digambarkan dengan titik pusat $\left(x_{0}+h, f\left(x_{0}+h\right)\right)$ terhadap kurva fungsi (8.2), dimana $h$ adalah bilangan positif atau negatif kecil. Lingkaran yang lainnya yaitu $C_{2}$ dengan jari-jari $f\left(x_{0}-h\right)$ dan pusat pada $\left(x_{0}-h, f\left(x_{0}-h\right)\right)$ digambarkan terhadap kurva fungsi $f(x)$ sedemikian sehingga menyinggung atau berpotongan dengan lingkaran $C_{1}$ secara eksternal atau ortogonal.

(1) Teknik Singgung Luar Lingkaran

Lingkaran $C_{2}$ akan menyinggung lingkaran $C_{1}$ secara eksternal jika:

$$
\begin{aligned}
f\left(x_{0}+h\right)+f\left(x_{0}-h\right) & =\sqrt{\left(x_{0}+h-x_{0}+h\right)^{2}+\left(f\left(x_{0}+h\right)-f\left(x_{0}-h\right)\right)^{2}}, \\
4 h^{2}-4 f\left(x_{0}+h\right) f\left(x_{0}-h\right) & =0, \\
h^{2}-\left\{\left\{f\left(x_{0}\right)+h f^{\prime}\left(x_{0}\right)+\frac{h^{2}}{2 !} f^{\prime \prime}\left(x_{0}\right)+\ldots\right\}\right. & \\
\left.\times\left\{f\left(x_{0}\right)-h f^{\prime}\left(x_{0}\right)+\frac{h^{2}}{2 !} f^{\prime \prime}\left(x_{0}\right)-\ldots\right\}\right\} & =0, \\
h^{2}\left\{1+\left(f^{\prime}\left(x_{0}\right)\right)^{2}-f\left(x_{0}\right) f^{\prime \prime}\left(x_{0}\right)\right\} & =\left(f\left(x_{0}\right)\right)^{2},
\end{aligned}
$$

dimana $h$ dapat disederhanakan menjadi

$$
h= \pm \frac{f\left(x_{0}\right)}{\sqrt{1+\left(f^{\prime}\left(x_{0}\right)\right)^{2}-f\left(x_{0}\right) f^{\prime \prime}\left(x_{0}\right)}}
$$

Oleh karena itu, dari persamaan (3.3) didapatkan approksimasi pertama dari akar, yaitu:

$$
x_{1}=x_{0} \pm \frac{f\left(x_{0}\right)}{\sqrt{1+\left(f^{\prime}\left(x_{0}\right)\right)^{2}-f\left(x_{0}\right) f^{\prime \prime}\left(x_{0}\right)}} .
$$

Secara umum, approksimasi dapat ditentukan dengan:

$$
x_{n+1}=x_{n} \pm \frac{f\left(x_{n}\right)}{\sqrt{1+\left(f^{\prime}\left(x_{n}\right)\right)^{2}-f\left(x_{n}\right) f^{\prime \prime}\left(x_{n}\right)}} .
$$

Kondisi cukup untuk kekonvergenan pada interval yang mengandung akar adalah:

$$
f\left(x_{n}\right) f^{\prime \prime}\left(x_{n}\right)<1+\left(f^{\prime}\left(x_{n}\right)\right)^{2} .
$$

(2) Teknik Perpotongan Ortogonal Lingkaran

Lingkaran $C_{2}$ akan berpotongan dengan lingkaran $C_{1}$ secara ortogonal jika:

$$
\begin{aligned}
f^{2}\left(x_{0}+h\right)+f^{2}\left(x_{0}-h\right) & =\left(x_{0}+h-x_{0}+h\right)^{2}+\left(f\left(x_{0}+h\right)-f\left(x_{0}-h\right)\right)^{2}, \\
4 h^{2}-2 f\left(x_{0}+h\right) f\left(x_{0}-h\right) & =0 \\
4 h^{2}-2\left\{\left\{f\left(x_{0}\right)+h f^{\prime}\left(x_{0}\right)+\frac{h^{2}}{2 !} f^{\prime \prime}\left(x_{0}\right)+\ldots\right\}\right. & \\
\left.\times\left\{f\left(x_{0}\right)-h f^{\prime}\left(x_{0}\right)+\frac{h^{2}}{2 !} f^{\prime \prime}\left(x_{0}\right)-\ldots\right\}\right\} & =0,
\end{aligned}
$$


dimana

$$
h= \pm \frac{f\left(x_{0}\right)}{\sqrt{2+\left(f^{\prime}\left(x_{0}\right)\right)^{2}-f\left(x_{0}\right) f^{\prime \prime}\left(x_{0}\right)}} .
$$

Oleh karena itu, dari persamaan (3.3) didapatkan approksimasi pertama dari akar, yaitu:

$$
x_{1}=x_{0} \pm \frac{f\left(x_{0}\right)}{\sqrt{2+\left(f^{\prime}\left(x_{0}\right)\right)^{2}-f\left(x_{0}\right) f^{\prime \prime}\left(x_{0}\right)}} .
$$

Secara umum, approksimasi dapat ditentukan dengan:

$$
x_{n+1}=x_{n} \pm \frac{f\left(x_{n}\right)}{\sqrt{2+\left(f^{\prime}\left(x_{n}\right)\right)^{2}-f\left(x_{n}\right) f^{\prime \prime}\left(x_{n}\right)}} .
$$

Kondisi cukup untuk kekonvergenan pada interval yang mengandung akar adalah:

$$
f\left(x_{n}\right) f^{\prime \prime}\left(x_{n}\right)<2+\left(f^{\prime}\left(x_{n}\right)\right)^{2} .
$$

\subsection{Contoh Kasus}

Dengan menggunakan teknik singgung luar lingkaran dengan titik pusat $\left(x_{0}, f\left(x_{0}\right)\right)$, akan dicari akar dari persamaan $f(x)=x^{2}-(1-x)^{5}$.

Penyelesaian:

Diberikan $f(x)=x^{2}-(1-x)^{5}$ untuk mencari akar dari persamaan $f(x)=0$, harus ditentukan terlebih dahulu $x_{0}$ sebagai taksiran awal, yaitu $x_{0}=0$ dan kriteria pemberhentian, yaitu $|f(x)|<5 \times 10^{-8}$. Hitung turunan pertama dari fungsi $f(x)$. Diperoleh

$$
f^{\prime}(x)=5 x^{4}-20 x^{3}+30 x^{2}-18 x+5 .
$$

Hasil dari iterasi ke 1 adalah $x_{1}$,dengan

$$
\begin{aligned}
x_{1} & =x_{0}-\frac{2 f\left(x_{0}\right)}{f^{\prime}\left(x_{0}\right)+\sqrt{1+\left(f^{\prime}\left(x_{0}\right)\right)^{2}}} \\
& =0,198039027185587
\end{aligned}
$$

Hitung nilai $|f(x)|$, yaitu

$$
\begin{aligned}
|f(x)| & =\left|(0,198039027185587)^{2}-(1-0,198039027185587)^{5}\right| \\
& =0,292496352876697>5 \times 10^{-8}
\end{aligned}
$$

Karena $|f(x)|>5 \times 10^{-8}$,maka iterasi dilanjutkan ke iterasi berikutnya yaitu iterasi ke 2 .

Hasil dari iterasi ke-2 adalah $x_{2}$,dengan

$$
\begin{aligned}
x_{2} & =x_{1}-\frac{2 f\left(x_{1}\right)}{\left(f^{\prime}\left(x_{1}\right)+\sqrt{1+\left(f^{\prime}\left(x_{1}\right)\right)^{2}}\right)}, \\
& =0,312214276192208 .
\end{aligned}
$$


Hitung nilai $|f(x)|$, yaitu

$$
\begin{aligned}
|f(x)| & =\left|(0,312214276192208)^{2}-(1-0,312214276192208)^{5}\right|, \\
& =0,056431872576240>5 \times 10^{-8} .
\end{aligned}
$$

Karena $|f(x)|>5 \times 10^{-8}$, maka iterasi dilanjutkan ke iterasi berikutnya yaitu iterasi ke 3. Iterasi akan terus dilanjutkan hingga $|f(x)|<5 \times 10^{-8}$. Dalam kasus diatas, iterasi akan berhenti pada iterasi ke-8, yaitu pada saat nilai $x_{7}=$ 0,345954646943483 .

Hasil dari iterasi ke- 8 adalah $x_{8}$,dengan

$$
\begin{aligned}
x_{8} & =x_{7}-\frac{2 f\left(x_{7}\right)}{\left(f^{\prime}\left(x_{7}\right)+\sqrt{1+\left(f^{\prime}\left(x_{7}\right)\right)^{2}}\right)}, \\
& =0,345954802055985 .
\end{aligned}
$$

Hitung nilai $|f(x)|$, yaitu

$$
\begin{aligned}
|f(x)| & =\left|(0,345954802055985)^{2}-(1-0,345954802055985)^{5}\right|, \\
& =0,000000022162327<5 \times 10^{-8} .
\end{aligned}
$$

Maka $x_{8}=0,345954802055985$ adalah salah satu akar dari $f(x)=x^{2}-(1-x)^{5}$.

\section{Kesimpulan}

Persamaan nonlinier dapat diselesaikan dengan menggunakan Metode Approksimasi Lingkaran melalui dua pendekatan, yaitu teknik singgung luar lingkaran dan teknik perpotongan ortogonal lingkaran. Untuk contoh kasus yang dibahas sebelumnya, dapat disimpulkan bahwa pemilihan taksiran awal sangat mempengaruhi banyaknya iterasi dalam mencari akar dari suatu persamaan nonlinier. Semakin dekat taksiran awal yang diambil dengan akar sejatinya, maka semakin cepat iterasi dalam menemukan akar dari suatu persamaan nonlinier.

\section{Ucapan Terima kasih}

Penulis mengucapkan terima kasih kepada ibu Dr. Lyra Yulianti, bapak Narwen M.Si dan bapak Zulakmal M.Si yang telah memberikan masukan dan saran sehingga makalah ini dapat diselesaikan dengan baik.

\section{Daftar Pustaka}

[1] Bartle, R.G. 2000. Introduction to Real Analysis. John Wiley and Sons, Inc. New York.

[2] Chapra, S.C. and R.P. Canale. 1985. Numerical Methods For Engineers. McGraw - Hill Company. Boston.

[3] Djohan, W. 2005. Diktat MA3171 Metode Numerik. ITB.

[4] Kanwar, V., S. Singh, J.R. Sharma and Mamta. 2003. New Numerical Techniques for Solving Nonlinear Equations. Department of Mathematics Sant Longowal Institute of Engineering and Technology. India.

[5] Munir, R. 2003. Metode Numerik. Informatika, Bandung. 
Menentukan Akar Persamaan Nonlinier dengan Metode Approksimasi Lingkaran 45

[6] Purcell, E.J., D. Verberg and S.E. Rigdon. 2003. Kalkulus edisi ke-8. Erlangga, Jakarta.

[7] Subakti, I. 2006. Metode Numerik. ITS. 